\title{
A NARRATIVA DA VIOLÊNCIA E DO TRAUMA EM MUITO ALÉM DO INVERNO, DE ISABEL ALLENDE
}

\section{LUANA DANIELA CIECELSKI}

RESUM 0: Esta resenha tem como objetivo abordar a narrativa da escritora chilena Isabel Allende, em sua obra Más allá del invierno traduzida no Brasil como Muito Além do Inverno, publicada em 2017 em seu país de origem e em 2018 em terras brasileiras. Iniciamos o trabalho apresentando um breve resumo do enredo, bem como as personagens da história. Em seguida passamos para uma breve reflexão a respeito do conteúdo da obra, com especial enfoque nas questões sociais trazidas pela autora, como a violência e o trauma, fortemente aparentes em sua narrativa. Para isso, contamos com o auxílio de alguns teóricos como Bragança (2008) e Lespada (2015). Ressalta-se, por fim, que o livro de Allende, por meio de sua narrativa, faz uma forte crítica às políticas norte-americanas para com os imigrantes.

PALAVRAS-CHAVE: Isabel Allende; literatura hispano-americana; narrativa da violência; narrativa do trauma.

Lançado no início de 2018 no Brasil, Muito além do inverno (Más allá del invierno) de Isabel Allende - autora de obras como A Casa dos espíritos (1982), A soma dos dias (2007), De amor e de sombra (1984), entre outras - apresenta três personagens cujas suas vidas se veem entrelaçadas por um acontecimento. São eles: Lucía, Richard e Evelyn, que vivem e se encontram no Brooklyn, em Nova Iorque. Lucía é uma chilena de meia idade divorciada e recém curada de um câncer de mama. Ela está nos Estados Unidos para um trabalho temporário em uma universidade, a convite de Richard, que é professor nessa mesma instituição. Ela mora em uma espécie de porão da casa dele, um anexo que ele costuma alugar e que colocou à disposição dela. 
Richard, por sua vez, é um americano de meia-idade e viúvo. Ele vive sozinho e apesar de estar decidido a não se envolver com ninguém por causa de dificuldades enfrentadas em seu casamento e em razão de desilusões do passado, há uma tensão amorosa entre ele e Lucía. Ele vive em uma situação financeira confortável e no início da história tem uma rotina tranquila, com preocupações apenas relacionadas a seus gatos e seu conforto

Já Evelyn é uma jovem de cerca de 19 anos que logo se torna central na narrativa. Ela nasceu na Guatemala e está nos Estados Unidos de forma ilegal. Veio atrás de sua mãe depois que seus dois irmãos foram mortos por uma gangue em seu país de origem. Ela trabalha para uma família rica, cuidando de um menino com paralisia cerebral. Seu patrão, o dono da residência, pertence a uma família historicamente ligada à criminalidade e, Evelyn suspeita, atua nos dias de hoje com tráfico humano.

A narrativa toda se passa em um período de cerca de três dias, durante uma nevasca que atinge a localidade. Essa tempestade e o frio interferem em suas rotinas, praticamente impedindo-os de sair de casa. Em determinado momento, no entanto, Richard vê um de seus gatos passar mal e precisa levá-lo em uma clínica veterinária. Quando está voltando para casa, ele não consegue frear por causa da neve e acaba colidindo com outro veículo, onde está Evelyn, que salta do carro apavorada. A batida não foi séria, mas danificou a fechadura do porta-malas do carro dela. Sem dizer nada, ela simplesmente entra no automóvel novamente e desaparece. Mas, antes disso, Richard consegue jogar em seu colo um cartão com o seu endereço e telefone, para que ela o procure futuramente para cobrar o conserto do veículo. Então, ele vai para casa.

Passadas algumas horas - Richard praticamente já tinha esquecido o acidente -, a campainha de sua casa toca e, ao atender, surpreende-se ao se deparar com a jovem do carro. Ele a convida para entrar, mas percebe que não consegue se comunicar bem com ela, que nervosa, gagueja e quase não consegue falar inglês. Ele chama então a vizinha/inquilina/amiga chilena, Lucía. A partir desse momento, seus destinos ficam muito ligados porque eles se veem diante de um problema que terão que resolver juntos. Além disso, se o que eles planejam der certo, terão um segredo a guardar juntos para sempre: o carro que Evelyn dirigia 
era de seu patrão, ela o havia pego escondido para ir até a farmácia, mas o acidente fez com que Evelyn descobrisse que havia o corpo de uma mulher no portamalas.

Evelyn não sabe o que fazer porque se a polícia for chamada, ela será, na melhor das hipóteses, deportada, e na pior delas, será considerada culpada pelo roubo do carro e pela morte daquela pessoa. Ela pede, então, ajuda a Richard e Lucía e, a partir disso, o enredo os leva a uma aventura na neve, rumo ao norte de Nova Iorque. Sozinhos, no meio do nada, com frio e um tanto assustados, eles acabam deixando vir à tona seus passados, suas histórias. Eles começam a conversar uns com os outros e isso os ajuda a resolver mais do que aquele problema que eles têm em mãos naquele momento, mas também suas vidas de forma geral.

É nesse ponto que a história ganha profundidade, pois o enredo em si não possui grande complexidade, podendo ser considerado até como um dos pontos fracos do livro. No entanto, Allende se destaca pela forma como trabalha com o emocional e o social. As denúncias que faz dão valor ao texto: o tráfico de pessoas, as dificuldades enfrentadas por aqueles que cruzam a fronteira do México com os EUA, a criminalidade dos países subdesenvolvidos da América Central e do Sul e principalmente a política de tratamento aos imigrantes adotada pelos Estados Unidos, especialmente a partir do Governo Trump.

A partir dessa leitura, vemos os imigrantes como pessoas sem quaisquer direitos, vivendo e trabalhando na clandestinidade, se sujeitando às situações mais difíceis, de exploração, de violência, o que os leva a atitudes impensadas como a tomada por Evelyn na história. Há também a questão dos motivos que levam essas pessoas a se sujeitar a essa vida, ou seja, o motivo que as leva a preferir uma vida clandestina a uma vida de legalidade em seus próprios países.

A personagem central dessa história, Evelyn, é um exemplo disso. Na Guatemala, onde ela nasceu, viu sua família ser destruída pelo grupo criminoso conhecido pelo nome MS-13. Ainda adolescente, seu irmão mais velho torna-se um integrante desse grupo, mas não demora para que a família o encontre morto, "cravado na ponte que cruzava o rio, coberto de sangue seco e excrementos, com um cartão no pescoço com as temíveis iniciais MS” (ALLENDE, 2018, p. 47). A partir daquele dia, a menina Evelyn, que estava prestes a completar 15 anos, "perdeu o apetite e a capacidade de alinhavar sílabas; gaguejava tanto que nem sua avó carinhosa tinha paciência para tentar entendê-la” (ALLENDE, 2018, p. 50). 
Cinco semanas depois, o grupo criminoso vai atrás do restante da família e ataca Evelyn e seu outro irmão. O jovem é morto, e Evelyn estuprada e também deixada para morrer com várias fraturas e ferimentos: "Estava consciente e abria os olhos, mas murmurava incoerências, não reconhecia a avó nem se dava conta de onde estava” (ALLENDE, 2018, p. 88).

Após o ocorrido, a comunidade decide que Evelyn precisa deixar o povoado o mais rápido possível, rumo aos Estados Unidos, porque o MS-13 não hesitaria em ir atrás dela para terminar o serviço. Nesse ponto, no entanto, o trauma em função de todos esses acontecimentos já está instalado na jovem.

A narrativa da violência e do trauma, é justamente, uma das características da narrativa hispano-americana contemporânea. Segundo Bragança (2008), o pós-boom buscou romper com os textos fantásticos e maravilhosos em favor de uma narrativa mais voltada para a realidade, ou, nas palavras do autor, questionando o "modelo de representação assumido pela nova narrativa latino-americana [o boom], propondo novas convenções de leitura a partir da desconstrução das fronteiras entre 'verdade' e 'ficção”' (BRAGANÇA, 2008, p. 130). Chega-se mesmo a propor uma desliteraturização, em favor de uma narrativa mais pura.

Dentro disso se encaixam os relatos, muitas vezes autobiográficos ou autoficcionais, a respeito da violência sofrida durante as ditaduras militares - como é o caso do livro As cartas que não chegaram de Mauricio Rosencof (2000) - , e também de outros tipos de violência - como guerras civis, holocausto, a violência promovida por grupos criminosos, pelo tráfico, ou mesmo por políticas internacionais como aquelas que fecham fronteiras e discriminam imigrantes -, trazendo junto nesse pacote as questões individuais, mas também sociais e políticas. Percebe-se muito disso ao longo da leitura de Muito Além do Inverno.

Lespada (2015) defende que essa narrativa sobre a violência e o trauma ganha muita força porque falar da dor, colocá-la em palavras, ajuda a silenciar essa dor. A literatura, segundo o autor, foi uma ferramenta encontrada para dar vazão ao horror:

durante ese período [das ditaduras], mientras el autoritarismo restringía la opinión pública por medio de censuras y persecuciones, la literatura - mayormente escrita y publicada en el exilio - se transformó en el espacio que apostó a dar cuenta del horror represivo. (LESPADA, 2015, p. 37) 
Ele aponta ainda que existe uma relação muito profunda entre a linguagem e a sociedade e que faz parte disso "escribir para suturar la pérdida, para restañar la hemorragia del habla, para conjurar la culpa del sobreviviente, para rechazar la muerte que significa el olvido, para que el 'gran crimen' no se repita” (LESPADA, 2015, pp. 47-48).

Além das características já citadas, Allende também mostra as diferenças sociais - outro tema recorrente na narrativa hispano-americana contemporânea - entre os personagens: há o americano que tem sua vida confortável; a chilena que sai de seu país (legalmente, mas sai) e que, assim como tantos, busca nos Estados Unidos um aperfeiçoamento profissional - mas que também têm marcadas em sua memória, lembranças da violenta ditadura do Chile, já que um de seus irmãos desapareceu nesse período - e claro, da imigrante ilegal, que vive em situação de extremo risco, tanto por sua clandestinidade quanto por sua situação de quase escrava junto à família violenta para a qual trabalha.

Vale destacar ainda que o título do livro, conforme entrevistas concedidas pela autora, é inspirado em uma famosa frase dita por Albert Camus - "No meio do inverno aprendi, finalmente, que havia em mim um verão invencível” - e que se refere, metaforicamente aos invernos (tempos ruins) pelos quais todas as pessoas ou mesmo os grupos sociais passam eventualmente. Para a autora, "o mundo, e em especial os Estados Unidos, está passando por um inverno perigoso, mas a humanidade superou momentos piores" (SALOMÃO, 2018).

Por isso, é possível dizer que há em toda a narrativa desse livro uma crítica, principalmente às políticas norte-americanas para com os imigrantes. Também há um desejo de denunciar a dura vida de grande parte da população que vive na América Central e do Sul. Fazendo isso, a autora não só trabalha a questão da dor e da violência, mas também traz à tona esses assuntos, fazendo com que as pessoas vejam a realidade e a discutam, para, talvez, futuramente mudá-la.

\section{REFERÊNCIAS}

ALLENDE, Isabel. Muito Além do Inverno. Trad. Luís Carlos Cabral. Rio de Janeiro: Bertrand Brasil, 2018. 293 p. 
BRAGANÇA, Maurício de. Entre o boom e o pós-boom: dilemas de uma historiografia literária latino-americana. Juiz de Fora: Revista Ipotesi, 2008, v. 12, n. 1, p. 119-133.

CUETO, Alonso. A hora azul. Trad. Eliana Aguiar. São Paulo: Objetiva, 2006. 336 p. LESPADA, Gustavo. Violencia y Literatura/ Violencia em la literatura. In: BASILE, Teresa (cord). Literatura y violencia en la narrativa latinoamericana reciente. La Plata: Universidad Nacional de La Plata, Facultad de Humanidades y Ciencias de la Educación. Instituto de Investigaciones en Humanidades y Ciencias Sociales (UNLP-CONICET). Centro de Estudios de Teoría y Crítica Literaria, 2015. Disponível em: <www.memoria.fahce.unlp.edu.ar/libros/pm.378/pm.378.pdf>. Acesso em: 10 jul 2019.

ROSENCOF, Maurício. As cartas que não chegaram. Trad. Leticia Wierzchowski. Rio de Janeiro: Record, 2013. 127 p.

SALOMÃO, Graziela. "Muito além do inverno", de Isabel Allende. Blog da Editora Record, 2018. Disponível em: <www.blogdaeditorarecord.com.br/2018/01/17/muito-alem-do-inverno-de-isabel-allende/>. Acesso em: 10 jul 2019. 